\title{
Alternative Asset Holdings by US Pension Funds Since the 2008 Financial Crisis
}

\author{
Stephen J. MacLean, PhD \\ Assistant Professor of Finance \\ FC Manning School of Business \\ Acadia University, Wolfville NS, United States
}

\begin{abstract}
Since the 2008 Financial Crisis, the percentage of alternative assets held by institutional investors has increased dramatically. The current study analyzes both the drivers and impacts of this increased allocation to alternative assets on US pension funds. Results indicate a significant divergence in asset allocations since the 2008 Financial Crisis. However, nä̈ve simulation analysis shows that, despite the argued motivation for the adaptation of alternatives by market research, those funds that adopted the highest level of alternatives would have actually performed worse during the 2008 Financial Crisis than those funds that made only modest allocation changes since that time.
\end{abstract}

Keywords: asset allocation, alternative assets, financial crisis

\section{Introduction}

The adaptation of alternative assets by institutional investors has grown significantly in the last decade, driven in large part by the substantial market correction and resulting asset allocation revisions coming out of the 2008 Financial Crisis. In their Global Alternatives Survey 2017, Towers Watson reports that global alternative assets under management (AUM) by institutional investors as of December 31, 2016, was $\$ 6.5 \operatorname{tln}^{1}$, up over three-fold from $\$ 2.0$ th in 2009. The authors also note that pension funds make up by far the largest institutional investor type, holding approximately one-third of global alternative AUM. Of particular importance is the fact that alternative assets are growing at a disproportionate rate relative to other asset classes since the 2008 Financial Crisis. Klement (2018) documents that alternative investments as a percentage of the global investment market have increased from 2.4 percent in 2000 to 6.2 percent in 2017. The most significant increase in growth observed in Klement's (2018) sample is over the latter ten years of his study when alternative assets grew at an annualized rate in excess of 12 percent. Despite this significant shift in asset allocations and increasing predominance of alternative investments in institutional portfolios, there has been surprisingly little literature dedicated to the allocation to alternative assets by pension funds over this period.

Prior to the 2008 Financial Crisis, pensions funds for the large part followed the ' $60 / 40$ equity-debt' allocation; that is, an allocation of 60 percent equity and 40 percent debt. One of the earlier works on pension fund allocation along these lines was presented by Ambachtsheer (1987), who proposes the argument that the 60/40 allocation for pension funds is appropriate. $^{2}$ He argues that the 60/40 allocation offers "significant downside protection for real returns over three to five-year investment horizons" and that a 100 percent bond allocation is as risky as a 100 percent equity allocation for going-concern portfolios. The general argument for a large allocation to equity by pension funds is supported by a number of academic studies prior to the 2008 Financial Crisis, including McCrory and Bartel (2003) who use simulation analysis to make the argument that equity is simply a better long-term investment given the long investment horizon of pension funds. A significant portion of the literature related to the asset allocation decisions of pension funds focuses on debt versus equity allocations. For instance, a large body of literature is dedicated to the relationship between fund maturity and the level of conservatism in asset allocations (Bikker et al. (2012); Davis and De Haan (2012); Boon et al. (2014)). Alestalo and Puttonen (2006) and Rauh (2009) show that fund participant age is positively (negatively) related to equity (fixed income) allocations while Boon et al (2014) show that the percentage of retired members is positively related to the allocation to risky assets. There has also beenresearch related to the average age of active fund participants versus the average age of all fund participants, but the results are inconclusive; Bikker et al. (2012) find that the average age of active participants impacts the equity allocation of funds while Gerber and Weber (2007) find that it's the average age of all participants, not active ones, that impacts allocations to real estate in pension funds.

\footnotetext{
${ }^{1}$ All figures are in US dollars unless otherwise stated.

${ }^{2}$ Ambachtsheer (1987), while examining specifically the 60/40 equity-debt allocation argues for an allocation between 40 to 70 percent in equity and other risky assets for risk minimization of long investment horizons.
} 
Meanwhile, Sutcliffe (2005) argues that it's plan-specific factors that impact the allocation to risky assets. In particular, he argues that in the absence of taxes, risk-sharing, and default insurance, the allocation to equity versus debt is determined solely by the risk-return preferences of the trustee and/or the employer. Similarly, Defau and de Moor (2018) find that employers (employees) that pay higher contributions to pension tend to have a higher (lower) allocation to risky assets. In addition, to fund characteristics, research has also shown that regulatory framework is also a determinant in pension fund asset allocation. Specifically, Boon et al. (2014) show that regulatory factors are actually a greater determinant of asset allocation amongst US, Canadian and Dutch pension funds than the funds' individual or institutional characteristics.

In specific relation to pension fund allocations to alternative asset classes, a number of studies have examined the fund characteristics that result in pension funds allocating capital to specific alternative asset classes, with particular attention being paid to hedge fund allocations. For instance, Bouvatier and Rigot (2013) find that allocation by US and Canadian pension funds to hedge funds is undertaken by large sophisticated funds with diverse asset class holdings. Interestingly, the authors find that while it is beneficial for funds to invest in hedge funds, the benefit is mainly a result of the decision to invest in these assets rather than the size of the allocation or the hedge fund investment returns. Jackwerth and Slavutskaya (2016) find that adding hedge funds not only adds to average pension fund performance for their sample of UK pension funds, but hedge funds themselves add more benefit than other alternative asset classes.

In addition to hedge funds, literature has also been dedicated to pension fund adaptation of other alternative asset classes. Andonov et al. (2014) document significant differences in real estate holdings for global pension funds, with large funds managing real estate portfolios in-house and generating higher returns than their smaller counterparts. The authors concluded that the difference in performance between large and small funds is driven by the larger funds being more easily able to invest in real estate internationally and at lower costs while smaller funds rely on external managers or funds of funds. Similarly, Boido and Fasano (2009) document that commodities are negatively correlated with traditional asset classes, lending further support for the diversification benefit of these assets for portfolios.

The current research adds to the body of literature concerning the asset allocations of pension funds by examining the factors that influence the adaption of alternative assets by US pension plans. One arguably positive outcome of the 2008 Financial Crisis is that it highlighted the importance of diversification within an investment portfolio (FraserSampson (2011)). In the investors' search for diversification, alternative assets have increased in popularity, with industry proponents including Seychuk and Sjogren (2017) of MacKenzie Investments advocating that in the absence of alternative investments "today's investors are faced with a potential return shortfall that comes with elevated volatility". They further say that there are three factors that represent the benefits of alternatives: potentially lower volatility, higher returns, and enhanced diversification.

The current study offers two important contributions to existing literature. Firstly, the research provides a direct test of how and what factors have led to the evolution of US pension fund allocations since the financial crisis of 2008. This contribution is important given that since the financial crisis pension fund allocations in large part have changed from the homogenous 60/40 equity/debt allocations of the past to significantly heterogenous allocations today. The current study helps shed light on the drivers of this divergence in allocations. Secondly, the current study offers a test of the potential impact of any changes in allocation on the protection of funds from significant downsideevents. Given the strong divergence observed in fund allocations post-2008, the current study addresses the question of whether these allocation changes have added materially to fund downside protection in a market selloff.

\section{Data and Methodology}

The current study utilizes the Public Plans Data (PPD) as offered by the Center for Retirement Research at Boston College, in partnership with the Center for State and Local Government Excellence and the National Association of State Retirement Administrators. The database covers fund level information from 2001 through 2017 for 180 plans representing 95 percent of state/local members in the United States.

The current study utilizes the full PPD database, eliminating any fund years that do not contain complete information utilized in the study as well as those funds that have less than five years of sample data. The resulting summary statistics are presented in Table 1 below. 


\begin{tabular}{|c|c|c|c|c|c|c|c|c|c|}
\hline \multirow[b]{2}{*}{ Fiscal Year } & \multirow[b]{2}{*}{ \# of Plans } & \multirow[b]{2}{*}{ AUM } & \multirow[b]{2}{*}{ Funded Ratio } & \multirow[b]{2}{*}{ Return Assump. (\%) } & \multicolumn{5}{|c|}{ Asset Mix (\%) } \\
\hline & & & & & Equities & Fixed Income & Real Estate & Alternative Assets & Cash \& Other \\
\hline 2001 & 122 & 14.3 & 1.01 & 8.06 & 55.6 & 33.8 & 4.3 & 2.6 & 3.7 \\
\hline 2002 & 129 & 13.0 & 0.94 & 8.06 & 53.9 & 34.9 & 4.6 & 2.8 & 3.8 \\
\hline 2003 & 134 & 12.9 & 0.89 & 8.03 & 55.8 & 32.3 & 4.3 & 3.0 & 4.6 \\
\hline 2004 & 140 & 14.3 & 0.87 & 7.99 & 59.4 & 29.2 & 4.0 & 3.3 & 4.1 \\
\hline 2005 & 145 & 15.4 & 0.85 & 7.98 & 59.8 & 28.5 & 4.4 & 3.8 & 3.5 \\
\hline 2006 & 147 & 16.3 & 0.85 & 7.96 & 58.7 & 28.2 & 4.8 & 5.0 & 3.3 \\
\hline 2007 & 151 & 18.2 & 0.86 & 7.94 & 58.1 & 26.6 & 5.2 & 6.2 & 3.9 \\
\hline 2008 & 152 & 16.5 & 0.83 & 7.93 & 52.8 & 28.3 & 6.2 & 8.8 & 3.9 \\
\hline 2009 & 155 & 13.1 & 0.77 & 7.91 & 51.2 & 28.4 & 5.7 & 10.1 & 4.6 \\
\hline 2010 & 155 & 14.5 & 0.75 & 7.87 & 50.6 & 27.5 & 5.4 & 11.7 & 4.8 \\
\hline 2011 & 155 & 16.5 & 0.74 & 7.81 & 51.1 & 25.1 & 5.8 & 12.8 & 5.2 \\
\hline 2012 & 154 & 16.6 & 0.72 & 7.76 & 49.6 & 24.7 & 6.3 & 15.2 & 4.2 \\
\hline 2013 & 150 & 17.3 & 0.72 & 7.71 & 50.7 & 22.8 & 6.2 & 15.8 & 4.5 \\
\hline 2014 & 153 & 20.3 & 0.73 & 7.67 & 50.9 & 21.8 & 6.1 & 16.4 & 4.8 \\
\hline 2015 & 154 & 20.3 & 0.74 & 7.63 & 48.8 & 22.4 & 6.5 & 17.4 & 4.9 \\
\hline 2016 & 155 & 19.9 & 0.73 & 7.52 & 47.6 & 22.2 & 6.6 & 18.3 & 5.3 \\
\hline 2017 & 89 & 20.4 & 0.70 & 7.38 & 48.5 & 21.3 & 5.6 & 19.1 & 5.5 \\
\hline Average & 143.5 & 16.5 & 0.81 & 7.84 & 53.1 & 26.9 & 5.4 & $\begin{array}{ll}10.1 \\
\end{array}$ & 4.4 \\
\hline
\end{tabular}

The final sample size, after removing those funds with missing or insufficient information, averages 143.5 funds per year, ranging from a low of 89 in 2017 to a high of 155 in multiple years. In total, there are 2,440 fund year observations in the resulting sample. PPD's classification of alternative assets includes hedge funds, private equity, commodities and 'other alternatives'.

The first observation that can be made from Table 1 is the significant reduction in AUM during the years 2008 and 2009 , with average AUM falling by nearly 30 percent from $\$ 18.2$ bln in 2007 to $\$ 13.1 \mathrm{bln}$ in 2009 . This result is unsurprising given the sharp decline in financial markets accompanying the 2008 Financial Crisis. Mirroring equity markets in general, average AUM recovered in a relatively short period of time and currently sits significantly higher than the 2009 lows at $\$ 20.4$ bln in 2017. What is related and interesting, however, is the pattern in Funded Ratio.

Funded Ratio shows year-over-year (YoY) decline in nearly every year of the sample, resulting in a decrease from 1.01 in 2001 to 0.70 in 2017. This is despite the fact thatthe average AUM in the sample is significantly higher in 2017 ( $\$ 20.4$ bln) compared with 2001 ( $\$ 14.3$ bln). A significant driver of the declining Funded Ratio is a near monotonic decrease in the average ActuariallyAssumed Rate of Return over the sample period. ${ }^{3}$

Of particular interest to the current study, it can be seen from Table 1 that plans have significantly increased their holdings of alternative assets since 2008. Specifically, the percentage of alternative assets in the average asset allocation has tripled in value since 2007, from 6.2 percent of AUM in 2007 to 19.1 percent in 2017. Figure 1 presents a graphical representation of the evolution of asset allocations over the sample period.

Figure 1 shows a significant increase in the rate of adaptation of alternative assets since the 2008 Financial Crisis. This increase in alternatives is fueled by a decline in allocations to both equities and fixed income asset classes, with alternative assets on pace to replace fixed income as the second-largest fund holding in the near future. What's interesting, however, is the continued significant holdings of equities in the average fund. One of the main motivations of the adaptation of alternative assets following the financial crisis was to reduce overall portfolio volatility (Seychuk and Sjogren (2017)). However, on the surface, it appears that funds have in large part simply replaced fixed income assets with alternatives. This is interesting as it has been widely observed and documented that fixed income and equity asset classes are negatively correlated, meaning that such a replacement strategy could actually impede diversification rather than strengthen it. This issue will be addressed in the Results Section of the current paper.

\footnotetext{
${ }^{3}$ Funded Ratio and Actuarially Assumed Rate of Return are negatively related, very similar to the relationship between bond price and yield. 


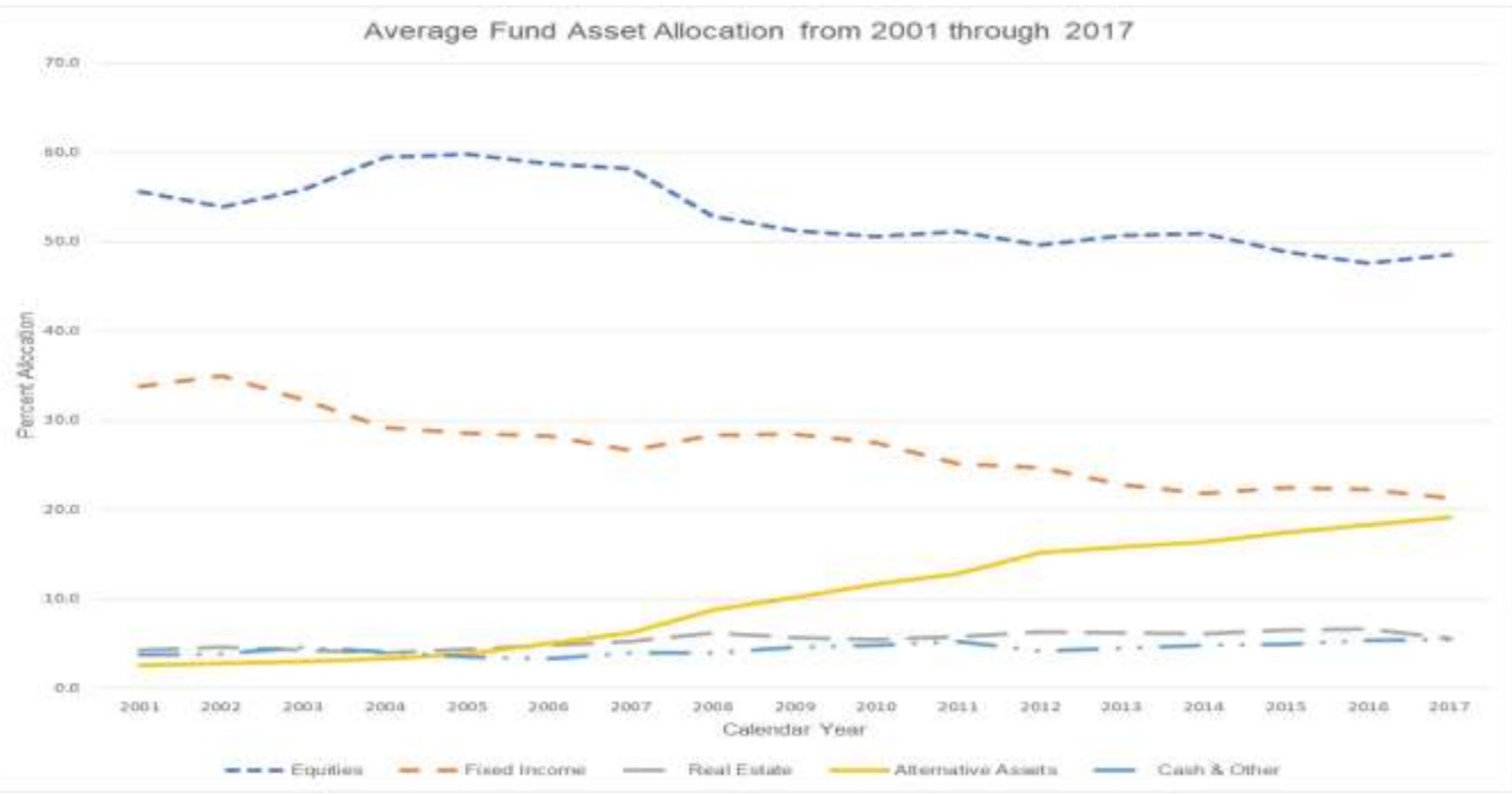

Statistical testing in the current study will utilize a number of variables of interest, starting with the depended variable under consideration. 'AA' represents in the below-outlined methodology the percentage of fund AUM invested in alternative assets. The underlying objective of the current study is two-fold: 1 . The study is an attempt to determine the drivers of alternative asset adaptation by pension funds and 2. To determine if funds are more or less susceptible to market shocks after their recent asset allocation changes than they would be prior to the asset allocation changes. In order to address these two objectives, the methodology employed in the current study is three-fold:

i. Comparative analysis of the characteristics of the funds prior to and following the increased adaptation of alternative assets following the Financial Crisis;

ii. Random effects unbalanced panel regression analysis to determine the drivers of alternative asset adaptation over the full sample period as well as the 2009 - 2016 post-FinancialCrisis period;

iii. Naïve simulation analysis to determine the impact of asset allocation changes on fund performance during a hypothetical financial crisis (namely, a repeat of the 2008 Financial Crisis).

\section{Results}

\subsection{Comparative Analysis}

The objective of the simple comparative analysis is to determine if there are any significant differences in fund characteristics both prior to and following the period of increased alternative asset adaptation. In order to accomplish this, funds are divided into quartiles based on their rate of adaptation of alternative assets between 2009 and 2016, with the resulting characteristics presented in Table 2 below. For example, Quartile 1 in Table 2 represents those funds that have the lowest rate of adaption, relative to their 2009 alternative asset holdings, over the period of 2009 to 2016.

Panel A of Table 2 represents the characteristics of each quartile at the start of the post-FinancialCrisis period (namely, 2009). What is interesting from this panel is there are no material differences in the fund characteristics between the funds that would subsequently become the highest adaptors of alternative assets (Quartile 4) and those that would become the lowest adaptors (Quartile 1). The highest adaptors have a slightly below average AUM and a slightly higher Actuarially Assumed Rate of Return and Funded Ratio, but these differences are not economically or statistically significant. Looking specifically at the asset mix, it is surprising that those funds that had the highest rate of adaption began the period with the lowest initial holdings of alternatives, and vice versa. While these initial differences in holdings fail to explain the significant change in allocations observed in Panel $\mathrm{B}$, they do suggest that funds that had little to no holdings of alternative assets prior to the financial crisis would become the largest holders in the sample period. This finding suggests a strong shift in allocation management for these funds, who one could argue had the lowest level of knowledge and/or experience with alternatives prior to 2008. 
Panels B and C of Table 2 represent, respectively, the 2016 fund characteristics and the change in characteristics over the 2009 to 2016 sample period. The average change in alternative asset holdings over the period was +8.2 percentage points, but there is a strong divergence amongst the four quartiles, with Quartile 4 funds increasing their alternative asset holdings by 23.9 percentage points of their asset mix while Quartile 1 funds actually reduced their alternative asset holdings by 2.9 percentage points.

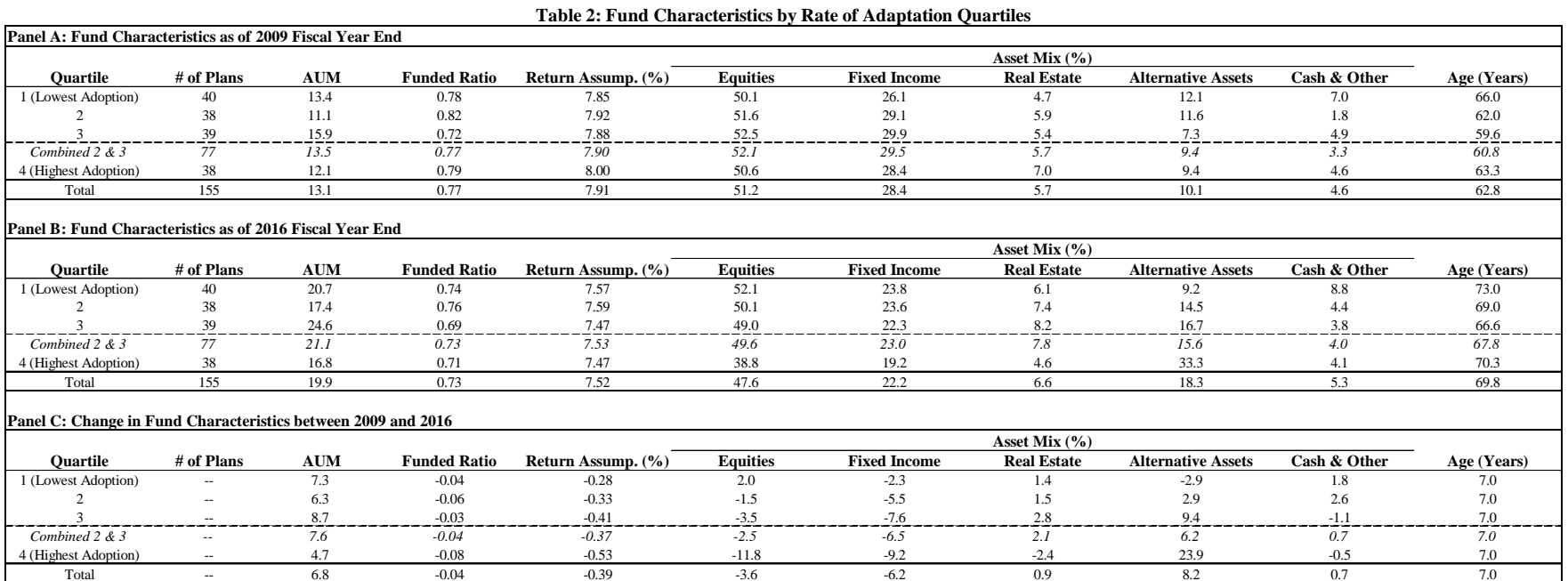

The resulting portfolios show that the Quartile 4 funds now hold one-third of their portfolio in alternative assets, significantly above the holdings of the average fund ( 18.3 percent). In addition, while there is no material difference in asset mixes in 2009, there are now much more heterogeneous asset mixes amongst the quartiles. Specifically, Quartile 4 funds hold significantly less of all other reported asset classes, in particular, equity, than their peers. It's also worth noting that this quartile of funds had a significantly lower appreciation of assets over the sample period as well as the largest decline in Funded Ratio and ActuariallyAssumed Rate of Return.

Fiqure 2: Quartile Asset Allocation Comparison for 2009 versus 2016


Figure 2 above provides a graphical representation of the change in allocations from 2009 to 2016. As can be seen, Quartile 1 funds have undergone at best modest asset allocation changes since the financial crisis, while Quartile 4 funds have made significant allocation changes through the reduction of both equity and fixed income securities coupled with a significant allocation increase to alternative assets.

\subsection{Regression Analysis}

Figure 2 demonstrates a significant divergence in fund asset allocations over the period of 2009 to 2016. During this time, most funds reduced equity and fixed income holdings while increasing holdings of real estate and alternative assets. To gain more insight into the drivers of these changes, the following panel regression is performed:

$$
\begin{aligned}
& \text { (1) } A A_{i, t}=\alpha+\beta_{\text {Size }} \text { Size }_{i, t}+\beta_{\text {Funded }} \text { Funded }_{i, t}+\beta_{R A} \text { ReturnAssumption }_{i, t}+\beta_{\text {Age }} \text { Age }_{i, t}+\beta_{\text {Return }} \text { 1YrReturn }_{i, t} \\
& +\beta_{S P} S P_{t}+\beta_{\text {Bond }} \text { Bond }_{t}+\beta_{R E} R E_{t}+\beta_{\text {Alternative }} \text { Alternative }_{t}+\beta_{\text {Cash } \text { Cash }_{i, t}+\varepsilon_{i, t}}
\end{aligned}
$$

where: 
- $\mathrm{AA}_{\mathrm{i}, \mathrm{t}}$ represents the percentage of alternative assets in fund $\mathrm{i}$ 's asset mix at time $\mathrm{t}$

- Size $_{i, t}$ represents the assets under management in USD billions of fund $i$ at time $t$

- Funded $_{i, t}$ represents the Funded Ratio of fund i at time $t$

- ReturnAssumption ${ }_{\mathrm{i}, \mathrm{t}}$ represents the Actuarially Assumed Rate of Return for fund $\mathrm{i}$ at time $\mathrm{t}$

- Age $_{i, t}$ represents the age of fund $i$ at time $t$

- 1 YrReturn $_{i, t}$ represents the 1-year return of fund $i$ at fiscal year-end $t$

- $\mathrm{SP}_{\mathrm{t}}$ represents the 1-year return of the $\mathrm{S} \& \mathrm{P} 500$ Composite Total Return Index as of fiscal year-end $\mathrm{t}$

- Bond ${ }_{t}$ represents the 1-year return of the S\&P 500 Bond Total Return Index as of fiscal year-end $t$

- $\mathrm{RE}_{\mathrm{t}}$ represents the 1-year return of the Vanguard Real Estate Total Return Index (USD) as of fiscal year-end $t$

- Alternative $e_{t}$ represents the 1-year return of a synthetic index consisting of 50 percent HFRI Composite Fund of Funds Total Return Index and 50 percent S\&P Listed Private Equity Total Return Index as of fiscal year-end t

- $\mathrm{Cash}_{\mathrm{t}}$ represents the 1-year return of the US Dollar 3 Month Deposit Total Return Index as of fiscal year-end $\mathrm{t}$

All fund-related information was obtained from the PPD database while the market proxy returns were obtained from Thomson Reuters Eikon.

The index returns in the above model are used to control for any impact that underlying market conditions may have on the rate of adaptation of alternative assets. The above model was run for the full sample period of 2001 through 2017 as well as the subsample period of 2009 through 2016 under the parameters of an unbalanced random effects panel regression. ${ }^{4}$ The results for both regressions for the two sample periods are presented in Table 3 below.

Table 3: Regression Results for Full Sample and Post-2008 Subsample Period

\begin{tabular}{|c|c|c|c|c|c|c|}
\hline \multirow[b]{2}{*}{ Variable } & \multicolumn{3}{|c|}{ Full Sample Period (2001 to 2017) } & \multicolumn{3}{|c|}{ Subsample Period (2009 to 2016) } \\
\hline & Coefficient & Standard Error & p-Value & Coefficient & Standard Error & p-Value \\
\hline$\alpha$ & 0.3907 & 0.051 & 0.000 & 0.4827 & 0.0713 & 0.000 \\
\hline Size & 0.0003 & 0.0001 & 0.045 & 0.0001 & 0.0002 & 0.777 \\
\hline Funded & -0.1229 & 0.0155 & 0.000 & -0.0279 & 0.0284 & 0.326 \\
\hline RtnAss & -4.0188 & 0.5675 & 0.000 & -4.3337 & 0.7830 & 0.000 \\
\hline Age & 0.0022 & 0.0003 & 0.000 & 0.0009 & 0.0004 & 0.035 \\
\hline 1YrRtn & -0.4563 & 0.0413 & 0.000 & -0.1628 & 0.0528 & 0.002 \\
\hline SP500 & 0.3956 & 0.0334 & 0.000 & 0.052 & 0.0496 & 0.294 \\
\hline Bond & 0.0469 & 0.035 & 0.180 & -0.1107 & 0.0616 & 0.072 \\
\hline RE & -0.0292 & 0.0118 & 0.013 & -0.0165 & 0.0144 & 0.251 \\
\hline Alternative & -0.0634 & 0.0233 & 0.007 & 0.0045 & 0.0304 & 0.884 \\
\hline Cash & -0.7265 & 0.1095 & 0.000 & -4.398 & 0.6064 & 0.000 \\
\hline Observations & 2,440 & & & 1,231 & & \\
\hline R2: & & & & & & \\
\hline within & 0.4358 & & & 0.1976 & & \\
\hline between & 0.0083 & & & 0.0098 & & \\
\hline overall & 0.1164 & & & 0.0092 & & \\
\hline
\end{tabular}

Over the full sample period, the model has a reasonable fit given the fit of traditional financial models. The within panel $\mathrm{R}^{2}$ for the full sample period is 0.4358 but falls to 0.1976 during the post-Financial Crisis subsample period. Overall, $\mathrm{R}^{2}$ is a reasonable 0.1164 for the full sample period but falls significantly to just 0.0092 for the subsample period.

Looking at the potential explanatory variables of interest, we see that ActuariallyAssumed Rate of Return is statistically significant and negative in both panels, indicating that funds with a lower rate of return assumption will tend to hold a higher portion of alternative assets in their asset mix. A similar negative statistically significant relationship is found for one-year fund return while the relationship between age and alternative asset holdings is positive, indicating that older funds tend to hold a higher percentage of alternative assets. For the full sample period, fund size is statistically and positively related to alternative asset holdings. This relationship is anticipated given economies of scales and various barriers to entry (in particular investment size) for many alternative asset classes.

${ }^{4}$ Regression (1) was also run under the parameters of an unbalanced fixed effects panel regression, producing highly consistent results as those reported in Table 3. 
Funded Ratio is statistically negatively related to alternative asset holdings for the full sample period, indicating that certisparibus a decline in funded status is accompanied by an increase in alternative asset holdings. Given that a large portion of the funding for an increase in alternative assets comes from higher return equities, this result is again as anticipated. However, an interesting observation from the full sample period is that poorer performing funds, as measured by their Funded Ratio, hold a lower allocation to alternative assets. This suggests that these funds are willing to accept increased volatility by holding a higher allocation to equities in order to close their funding shortfall rather than favoring reduced volatility to limit the further decline in their Funded Ratio. This result, however, is statistically insignificant in the subsample period.

Also of interest from Table 3 is the significance of the market proxy variables. While the results are statistically significant for all but one market proxy in the full sample period, they are insignificant for all but Cash in the subsample period. This is an indication that while over the full sample market performance was a driver in the allocation of funds to alternative assets, managers largely ignored market performance in the post-financial crisis period when making their decisions to adopt alternatives into their asset mix.

For robustness, Regression (1) was performed with the calendar year dummy variables replacing the index returns as the control variables for underlying market conditions. The unreported results of this regression were largely consistent with those presented in Table 3 above.

\subsection{Simulated Returns}

In addition to studying the drivers of adaptation of alternative assets, the current study also aims to examine the impact of such changes on the downside risk of funds. In order to accomplish this, the current study simulates the hypothetical performance of Quartiles 1 through 4 funds given a repeat of the 2008 Financial Crisis.

In order to simulate the performance of the fund quartiles, the current study applies the monthly index performance for the asset classes of interest for the six-month period of October 2008 through March 2009, inclusive. This period is chosen as it represents arguably the height of the 2008 Financial Crisis and encompasses the most significant period of market volatility.

The simple repetition of the performance of funds during the 2008 Financial Crisis is not ideal as it entails a number of assumptions. First and foremost, by measuring fund protection against one specific event we are assuming that this specific event is exactly repeatable, the probability of which is zero. In addition, the simulation assumes that index returns represent a measure of asset class performance for the average fund. Again, this is a strong assumption as it fails to address, at a minimum, security selection at the fund level. Finally, the simulation must address, amongst other things, the issue of fund rebalancing. The results presented below offer two rebalancing methods: perfect monthly rebalancing and no rebalancing over the six-month period. For clarity, perfect monthly rebalancing refers to resetting the asset allocations to those found in Table 2 each month while no rebalancing refers to not resetting the allocations over the test period and thus allowing the asset mix to drift with relative asset class performance. In short, while the simulated returns reported below are not perfect, they do however allow for general conclusions to be drawn concerning the changing asset mixes of funds since 2009.

Table 4 below shows the resulting simulated returns based on asset class weights for the four quartiles as found in Table 2 above. For example, Quartile 1 funds have a six-month simulated return, based on their 2009 asset mix as found in Table 2, of -32.21 percent. Replacing the 2009 asset mix with the 2016 asset mix for these same funds and assuming monthly rebalancing, the resulting simulated return is -32.45 percent, a difference of 25 basis points. The conclusion is thus that these same funds would have performed 25 basis points worse during the height of the financial crisis with their 2016 asset mix than they would have with their 2009 asset mix.

Table 4: Simulated Returns for 2009 and 2016 Asset Allocations

\begin{tabular}{|c|c|c|c|c|c|c|}
\hline \multirow[b]{2}{*}{ Quartile } & \multicolumn{3}{|c|}{ Monthly Rebalancing } & \multicolumn{3}{|c|}{ No Rebalancing } \\
\hline & 2009 Simulated Return & 2016 Simulated Return & Difference & 2009 Simulated Return & 2016 Simulated Return & Difference \\
\hline 1 (Lowest Adoption) & $-32.21 \%$ & $-32.45 \%$ & $-0.25 \%$ & $-9.10 \%$ & $-9.36 \%$ & $-0.26 \%$ \\
\hline 2 & $-33.59 \%$ & $-34.96 \%$ & $-1.37 \%$ & $-9.74 \%$ & $-10.02 \%$ & $-0.28 \%$ \\
\hline 3 & $-31.62 \%$ & $-35.97 \%$ & $-4.35 \%$ & $-9.25 \%$ & $-10.28 \%$ & $-1.03 \%$ \\
\hline Combined $2 \& 3$ & $-32.64 \%$ & $-35.49 \%$ & $-2.85 \%$ & $-9.50 \%$ & $-10.16 \%$ & $-0.66 \%$ \\
\hline 4 (Highest Adoption) & $-32.71 \%$ & $-36.97 \%$ & $-4.26 \%$ & $-9.53 \%$ & $-9.51 \%$ & $0.02 \%$ \\
\hline Total & $-32.50 \%$ & $-35.09 \%$ & $-2.58 \%$ & $-9.39 \%$ & $-9.80 \%$ & $-0.41 \%$ \\
\hline
\end{tabular}

Table 4 provides a number of interesting conclusions related to the downside protection of funds as a result of their changing asset mix. The first observation is that nearly universally across the table, under both rebalancing assumptions, funds are worse off with the 2016 asset mixes than with the 2009 asset mixes. Overall, the average fund is between 0.41 percent and 2.58 percent worse off given its asset allocation changes depending on the rebalancing assumption employed. 
An even more pertinent result to the current study is that the most unfavorable change in performance is for funds that were the largest adaptors of alternative assets, with Quartile 3 and 4 funds performing in significantly worse than the two other quartiles regardless of the rebalancing assumption employed with the sole exception of Quartile 4 under no rebalancing.

In order to examine more closely the drivers behind the significant change in performance for the largest adaptors of alternative assets, attribution analysis under the assumption of perfect monthly rebalancing for each quartile of funds is found in Table 5 below.

Table 5: Attribution Analysis for 2009 versus 2016 Return Difference Given Perfect Monthly Rebalancing

\begin{tabular}{|c|c|c|c|c|c|c|}
\hline \multirow[b]{2}{*}{ Quartile } & \multicolumn{6}{|c|}{ Atribution Analysis } \\
\hline & Equities & Fixed Income & Real Estate & Alternative Assets & Cash \& Other & Total \\
\hline 1 (Lowest Adoption) & $-0.25 \%$ & $-0.63 \%$ & $-0.43 \%$ & $0.46 \%$ & $0.60 \%$ & $-0.25 \%$ \\
\hline 2 & $0.16 \%$ & $-1.59 \%$ & $-0.43 \%$ & $-0.42 \%$ & $0.91 \%$ & $-1.37 \%$ \\
\hline 3 & $0.45 \%$ & $-2.04 \%$ & $-0.87 \%$ & $-1.53 \%$ & $-0.36 \%$ & $-4.35 \%$ \\
\hline Combined $2 \& 3$ & $0.30 \%$ & $-1.81 \%$ & $-0.63 \%$ & $-0.95 \%$ & $0.24 \%$ & $-2.85 \%$ \\
\hline 4 (Highest Adoption) & $1.39 \%$ & $-2.57 \%$ & $0.72 \%$ & $-3.63 \%$ & $-0.17 \%$ & $-4.26 \%$ \\
\hline Total & $0.43 \%$ & $-1.72 \%$ & $-0.27 \%$ & $-1.26 \%$ & $0.24 \%$ & $-2.58 \%$ \\
\hline
\end{tabular}

Focusing on the underperformance of Quartile 3 and 4 funds, we see that both quartiles benefit from their reduction in allocation to equities over the 2009 to 2016 period, with Quartile 4 funds benefiting nearly 140 basis points from their underweighting of poor performing equities. The positive attribution associated with equities, however, is easily trumped by the underperformance associated with the funds changing allocations to fixed income and alternative assets. Significant reductions in fixed income holdings cost each of Quartiles 3 and 4 funds in excess of 200 basis points in relative performance, indicating that the shift out of fixed income securities cost these funds in excess of 2 percent in performance relative to 2009 holdings. Compounding the problem of underperformance associated with fixed income securities is the fact that a large portion of the reduced allocation in fixed income securities appears to have been placed in alternative assets, which themselves performed poorly over the six-month period of interest. Thus, increased allocation to alternative assets resulted in negative attribution of 153 basis points and 363 basis points for Quartiles 3 and 4 funds, respectively. While these simulation results are naïve and less than ideal, they lend support for the fact that the reallocation of funds post the 2008 Financial Crisis may actually hinder fund performance during extreme market downturns.

\section{Conclusion}

The rate of adaptation of alternative assets by US pension funds has increased significantly since the 2008 Financial Crisis, with the average fund nearly doubling its holdings in this relatively short period of time. Regression analysis shows that Funded Ratio and Actuarially Assumed Rate of Return both play a statistically and economically significant role in this adaption over the full sample period of 2001 to 2017.

The general motivation for the increased adaptation of alternatives by both retail and institutional investors is linked to increased diversification and lower portfolio volatility. However, the current study shows that the asset allocation changes implemented since 2009 have not only hindered fund growth and Funded Ratio over this time but may have actually deteriorated downside protection as measured by the simulation of index returns during the height of the 2008 Financial Crisis.

The current study offers an interesting perspective on the usefulness of alternative assets in an investment portfolio. And while the study's focus is very narrow in scope, its general conclusions lead to a number of potential areas of further research, the most predominate being an examination of the general cost of alternative assets (namely the lost return associated with reallocating from equity securities) relevant to the perceived versus actual benefits (namely increased diversification and reduced volatility). This is a particularly pertinent topic as the recent flow of funds into alternatives has significantly increased demand for investment alternatives and as such has negatively impacted their performance (Alternative Investments 2020 (2015)).

\section{References}

Alternative Investments 2020: The Future of Alternative Investments. (2015). World Economic Forum. http://www3.weforum.org/docs/WEF_Alternative_Investments_2020_Future.pdf

Alestalo, Noora and VesaPuttonen. 2006. "Asset Allocation in Finnish Pension Funds." Journal of Pension Economics and Finance, February: 27-44.

Ambachtsheer, Keith. (1987). "Pension Fund Asset Allocation: In Defense of a 60/40 Equity/Debt Asset Mix." Financial Analysts Journal, September: 14-24. 
Andonov, Alexsandar, Piet Eichholtz, and Nils Kok. (2014). "Intermediate Investment Management in Private Markets: Evidence from Pension Fund Investments in Real Estate." Journal of Financial Markets, November: 73-103.

Bikker, Jacob, Dirk Broeders, David Hollanders, and Eduard Ponds. (2012). "Pension Funds' Asset Allocation and Participant Age: A Test of the Life-Cycle Model." The Journal of Risk and Insurance, September: 595-895.

Boido, C. and Fasano, A. (2009). "Alternative Assets: A comparison between Commodities and

Traditional Asset Classes." ICFAI Journal of Derivative Markets,April:74-105.

Boon, Ling-Ni, Marie Briere, and Sandra Rigot. (2014). "Does Regulation Matter? Riskiness and Procyclicality in Pension Asset Allocation." SSRN WP No. 12/2014-054.

Bouvatier, Vincent and Sandra Rigot. (2013)."Pension Funds' Allocations to Hedge Funds: An Empirical Analysis of US and Canadian Defined Benefit Plans."Applied Economics, 45, 3701-3710.

Davis, Philip and Leo De Haan. (2012). "Pension Fund Finance and Sponsoring Companies." Journal of Pension Economics and Finance, February: 439-463.

Defau, Laurens andLieven De Moor. (2018). “The Impact of Plan and Sponsor Characteristics on Pension Funds' Asset Allocation and Currency Diversification."Journal of Asset Management, January: 27-37.

Fraser-Sampson, G. (2010). Alternative assets: Investments for a post-crisis world,JohnWiley and Sons Publications.

Gerber, David and René Weber. (2007). "Aging, Asset Allocation, and Costs: Evidence for the Pension Fund Industry in Switzerland." IMF WP 07/29.

Jackwerth, Jens and Anna Slavutskaya. (2016). "The Total Benefit of Alternative Assets to Pension Fund Portfolios." Journal of Financial Markets, November: 25-42.

Klement, Joachim. (2018). “The Global Alternative Investment Market - Where it is and where it's going." Fidante Partners. https://www.fidante.com/-/media/Fidante/resources/Articles/20180906_AI_FINAL.pdf

McCroy, Robert and John Bartel. (2003). "Reinventing Pension Actuarial Science: A Critique." The Pension Forum, January: 17-23.

Rauh, Joshua. (2009). "Risk Shifting versus Risk Management: Investment Policy in Corporate Pension Plans." The Review of Financial Studies, July: 2687-2733.

Seychuk, A. and Sjogren, K. (2017) Dealing with volatility and diversification through the use of alternative investments, https://www.mackenzieinvestments.com/en/investment-teams/mackenzie-systematic-strategiesteam/dealing-with-volatility-and-diversification.

Sutcliffe, Charles. (2005). “The Cult of Equity for Pension Funds: Should It Get the Boot?" Journal of Pension Economics andFinance, March: 57-85.

Willis Towers Watson's Global Alternatives Survey 2017. file://C:/Users/Stephen\%20MacLean/Downloads/GlobalAlternatives-Survey-2017-Final.pdf 